\title{
MESEJ KERUKUNAN RUMAH TANGGA DALAM SENI KATA LAGU DIKIR AL-BURDAH DI SARAWAK
}

\section{(The Message of Household Harmony in the Song Lyrics of Dikir al-Burdah among the Malay Community in Sarawak)}

Noryamisma Ismail

isma_wani86@yahoo.com

Mohd. Zariat Abdul Rani

zariat@upm.edu.my

Fazilah Husin

fazilahh@upm.edu.my

Norazlina Haji Mohd Kiram

noraz@upm.edu.my

Fakulti Bahasa Moden dan Komunikasi, Universiti Putra Malaysia.

Published online: 3 December 2018

To cite: Noryamisma Ismail, Mohd. Zariat Abdul Rani, Fazilah Husin, Norazlina Haji Mohd Kiram. (2018). Mesej Kerukunan rumah tangga dalam seni kata lagu dikir al-Burdah di Sarawak Malay Literature $31(2), 287-310$.

\begin{abstract}
Abstrak
Kajian ini bertitik tolak daripada amalan masyarakat Melayu di Sarawak yang menjadikan dikir al-Burdah antara acara yang dipersembahkan dalam majlis perkahwinan. Kajian ini meneliti secara khusus seni kata lagu dikir al-Burdah yang berkaitan dengan perkahwinan. Objektif kajian ini, mengenal pasti mesej yang terkandung dalam seni kata lagu dikir al-Burdah berkaitan perkahwinan, dan seterusnya menilai kesejajaran mesej tersebut dengan ajaran Islam. Kajian ini menggunakan pendekatan analisis teks, dengan menjadikan lima seni kata lagu dikir al-Burdah yang
\end{abstract}


diperoleh daripada Pertubuhan An-Nur, Kampung Melango Baru, Daerah Saratok, Sarawak, sebagai teks. Analisis mendapati bahawa kesemua seni kata lagu dikir al-Burdah yang dikaji mengutarakan mesej tentang kerukunan rumah tangga, yang didapati sejajar dengan ajaran Islam seperti yang terkandung dalam al-Quran dan Hadis.

Kata kunci: dikir al-Burdah; Pertubuhan An-Nur, Kampung Melango Baru; majlis perkahwinan; mesej; Islam

\begin{abstract}
This study is based on the practice of the Malay community in Sarawak which makes the performance of dikir al-Burdah as part of the event in the wedding ceremony. In practice, dikir al-Burdah is usually presented in the morning as a starting for a bersanding ceremony, with the intention of applying for the ceremony. Based on its role in the Malay wedding ceremony in Sarawak, this study examined specifically the art of the song dikir al-Burdah related to marriage. This study outlines two objectives, namely identify the messages contained in the art of the word dikir al-Burdah related to marriage, and then evaluate the alignment of the message with the teachings of Islam. This study adopts a text analysis approach, by making five songs of the word dikir al-Burdah derived from the An-Nur Organization, Kampung Melango Baru, Saratok District, Sarawak, as texts. The analysis found that all the songs of the word dikir al-Burdah which were examined addressed the message of household harmony, which were found to be in line with the teachings of Islam as contained in the al-Qur'an and Hadith.
\end{abstract}

Keywords: dikir al-Burdah; An-Nur Organization, Kampung Melango Baru, wedding ceremony, message, Islam

\title{
PENDAHULUAN
}

Masyarakat Melayu di Sarawak kaya dengan adat resamnya yang tersendiri (Junaidah, 2018, p. vii). Kekayaan adat resam ini dapat diamati dalam majlis keraian yang disambut bersempena dengan peristiwa atau upacara tertentu, antaranya termasuklah majlis perkahwinan. Ajaran Islam menggalakkan majlis diadakan bagi meraikan pasangan yang baru bernikah (walimah alurus) untuk mengisytiharkan perkahwinan mereka kepada orang ramai $(\mathrm{Hj}$. Abd. Kadir, 2002, p. 127; Sheikh Fuad Saleh, 2012, p. 115). Seperti yang digariskan dalam syariat Islam, pasangan lelaki-perempuan diwajibkan 
untuk mengikat tali pernikahan bagi membolehkan mereka hidup berkelamin (Hj. Abd. Kadir, 2002, p. 20). Ikatan pernikahan dianggap sah sekiranya melibatkan pasangan antara lelaki dengan perempuan, wali yang mewakili pihak perempuan, saksi pernikahan, serta akad atau lafaz ijab dan kabul yang disahkan oleh para saksi (Hj. Abd. Kadir, 2002, p. 13; Sheikh Fuad Saleh, 2012, pp. 89-90). Dalam amalan masyarakat Melayu di Sarawak, selain upacara pernikahan atau ijab kabul itu sendiri, majlis perkahwinan turut diisi dengan upacara seperti belulut atau menepung tawar pengantin selepas akad nikah, berpacar atau berinai, jamuan kenduri, perarakan serta persandingan pengantin (disebut berbanding), menyembak atau pengantin lelaki membatalkan air sembahyang dengan menyentuh ubun-ubun pengantin perempuan, dan makan nasi temuan antara pengantin dengan kaum keluarga dan sahabat handai (Raslie, 1988, pp. 146-152; Abang Yusuf, 2008, pp. 82-107).

Sebelum upacara persandingan, majlis perkahwinan masyarakat Melayu di Sarawak lazimnya diserikan dengan acara tertentu seperti bacaan barzanji dan dikir al-Burdah (Raslie, 1988, p. 152). Khatam al-Quran dan bacaan barzanji pada kebiasaannya diadakan dalam majlis perkahwinan masyarakat Melayu. Persembahan dikir al-Burdah pula secara khusus dipersembahkan dalam majlis perkahwinan masyarakat Melayu di Sarawak. Di sesetengah kawasan, dikir al-Burdah juga disebut sebagai "zikir burdah" atau "zikir rebana" (Raslie, 1988, p. 132; Hj. Muhammad Bukhari, 1994, p. 130). Antara kawasan yang didapati masih mempersembahkan dikir al-Burdah termasuklah Kampung Hulu di Daerah Sri Aman dan Kampung Sessang di Daerah Kalaka (Raslie, 1988, p. 132; Hj. Muhammad Bukhari, 1994, pp. 127-132). Dalam amalannya di Sarawak, dikir al-burdah lazimnya dipersembahkan pada sebelah pagi sebagai permulaan majlis kepada upacara persandingan yang dianggap acara kemuncak majlis perkahwinan. Antara tujuan dikir al-Burdah dipersembahkan adalah untuk memohon keberkatan majlis yang diadakan (Raslie, 1988, p. 152). Selain majlis perkahwinan, persembahan dikir al-Burdah di Sarawak turut mengisi majlis seperti pembukaan kampung baharu dan mendirikan rumah baharu (Raslie, 1988, p. 132; Hj. Muhammad Bukhari, 1994 p. 132).

Sehingga kini dan sepanjang yang diketahui, telah ada beberapa kajian tentang persembahan dikir al-Burdah di Sarawak. Antaranya termasuklah tulisan Raslie bertajuk "Beberapa Aspek Kebudayaan Masyarakat Melayu Sarawak" (1988). Sebagai salah satu bab yang dirangkumkan dalam sebuah buku yang membicarakan tentang adat resam masyarakat Sarawak. Raslie 
(1988) merakamkan secara umum tentang masyarakat Melayu di Sarawak. Di bawah subjudul "Kesenian", tulisan Raslie mencatatkan tentang dikir al-Burdah (dinyatakan sebagai "zikir burdah") sebagai satu bentuk seni persembahan yang dikatakan berkaitan dengan tradisi al-Qasidah al-Mimiyah yang memuji Nabi Muhammad SAW. Dari segi tatacara persembahan, Raslie mencatatkan bahawa dikir al-Burdah dipersembahkan secara berkumpulan, iaitu seramai 21 orang yang diketuai oleh seorang ketua yang dipanggil "khalifah". Ahli yang duduk dalam tiga barisan menyanyikan lagu dikir yang dimulai serta diakhiri dengan ucapan selawat atas Nabi Muhammad SAW. Alunan lagu dikir juga diiringi dengan paluan rebana atau gendang daripada kulit kambing atau lembu (Raslie, 1988, p. 132).

Hj. Muhammad Bukhari menulis tentang dikir al-Burdah menerusi tulisannya yang bertajuk "Dendangan Puisi al-Burdah di Kampung Sessang, Sarawak" (1994, pp. 127-132). Seperti Raslie (1988), Hj. Muhammad Bukhari mengaitkan persembahan dikir al-Burdah di Sarawak dengan tradisi al-Qasidah al-Mimiyah (Hj. Muhammad Bukhari, 1994, p. 127). Dari segi tatacara persembahan, Hj. Muhammad Bukhari menjelaskan bahawa dikir al-Burdah lazimnya dipersembahkan secara berkumpulan dengan ahlinya seramai 21 orang, tetapi adakalanya boleh menjangkau sehingga 50 orang. Menurut Hj. Muhammad Bukhari, persembahan dikir al-Burdah boleh dilakukan sama ada secara duduk atau berjalan. Ahli kumpulan berada dalam tiga barisan yang setiap satunya mengandungi tujuh orang ahli. Seorang ketua yang digelar "khalifah" berada paling hadapan dan menghadap khalayak. Nyanyian lagu dikir dimulai serta disudahi dengan selawat atas Nabi Muhammad SAW. Paluan rebana merupakan satu-satunya alat muzik yang dimainkan. Rebana dipalu dengan beberapa jenis paluan yang berbeza. Dalam satu persembahan lazimnya mendendangkan lima buah lagu yang secara keseluruhannya mengambil masa satu hingga dua jam (Hj. Muhammad Bukhari, 1994, pp. 129-131).

\section{PERMASALAHAN KAJIAN}

Pengamatan terhadap korpus ilmu semasa tentang dikir al-Burdah di Sarawak di atas menjelaskan beberapa perkara penting. Dikir al-Burdah di Sarawak ditanggapi sebagai seni persembahan yang bersifat keislaman. Tanggapan ini jelas apabila dikir al-Burdah dikaitkan dengan tradisi alQasidah al-Mimiyah serta tatacara persembahannya yang dianggap tidak bercanggah dengan syariat Islam. Tidak kurang penting, nyanyian lagu dikir itu sendiri yang dimulai dan diakhiri dengan selawat atas junjungan besar 
Nabi Muhammad SAW. Dengan bentuk persembahan serta isi kandungan lagu seperti yang dideskripsikan dalam sorotan kajian di atas, maka tidak hairan jika persembahan dikir al-Burdah menjadi antara acara yang mengisi majlis perkahwinan masyarakat Melayu di Sarawak. Seperti yang telah dinyatakan di atas, agama Islam menganjurkan majlis perkahwinan bagi mengisytiharkan ikatan pernikahan yang termeterai. Memandangkan masyarakat Melayu di Sarawak rata-rata beragama Islam, maka penganjuran majlis perkahwinan cenderung dilihat sebagai usaha murni untuk menyahut seruan agama. Dalam konteks ini, dikir al-Burdah dipersembahkan dengan tujuan memohon keberkatan majlis perkahwinan yang diadakan. Adalah jelas bahawa seni persembahan dikir al-Burdah memainkan peranannya yang tersendiri dalam majlis perkahwinan masyarakat Melayu di Sarawak. Hal ini mengundang satu penelitian khusus terhadap lagu dikir al-Burdah yang berkaitan dengan perkahwinan.

Penelitian ini bagi menjawab dua persoalan kajian, iaitu apakah mesej yang terkandung dalam seni kata lagu dikir al-Burdah yang berkaitan dengan perkahwinan dan, adakah mesej itu sejajar dengan ajaran Islam? Soal kesejajaran ini relevan kerana dikir al-Burdah di Sarawak telah menjadi satu seni persembahan dalam majlis perkahwinan dan juga majlis atas anjuran Islam.

\section{KAWASAN DAN BAHAN KAJIAN}

Kajian ilmiah sedia ada sehingga kini mengenal pasti beberapa kawasan di Sarawak yang menjalankan kegiatan persembahan dikir al-Burdah. Antaranya termasuklah Kampung Hulu di Daerah Sri Aman dan Kampung Sessang di Daerah Kecil Kabong (Raslie, 1988, p. 132; Hj. Muhammad Bukhari, 1994, pp. 127-132). Dalam konteks persembahan dikir al-Burdah dalam majlis perkahwinan, kegiatan di Kampung Melango Baru mengundang penelitian yang lebih menarik.

Tinjauan awal terhadap persembahan ini yang berpusat di Kampung Melango Baru membolehkan kajian ini mendekati Pertubuhan An-Nur yang merupakan sebuah kumpulan kebudayaan tempatan yang giat mempersembahkan dikir al-Burdah. Pertubuhan ini ditubuhkan secara rasmi pada tahun 2009 dan dipengerusikan oleh Haji Mohamed Usup bin Rahman. Dalam tinjauan awal itu, Haji Mohamed Usup telah menyerahkan sebuah kompilasi seni kata lagu dikir al-Burdah yang dijadikan rujukan oleh anggota Pertubuhan An-Nur, Kampung Melango Baru untuk latihan dan persembahan. Kompilasi ini disalin daripada versi asal milik Haji Mohamed 
Usup. Salinan kompilasi ini mengandungi lapan buah seni kata lagu dikir al-Burdah. Daripada jumlah tersebut, bacaan awal mendapati bahawa enam seni kata lagu dikir al-Burdah berkaitan perkahwinan. Maklumat diperoleh melalui wawancara, Pertubuhan An-Nur, Kampung Melango Baru yang giat menerima undangan untuk persembahan dikir al-Burdah di majlis perkahwinan (Wawancara dengan Haji Mohamed Usup bertarikh 8 Mac 2013). Sejajar dengan fokus terhadap persembahan dikir al-Burdah dalam majlis perkahwinan masyarakat Melayu di Sarawak, kajian ini menjadikan lima seni kata lagu berkaitan perkahwinan yang diperoleh daripada Pertubuhan An-Nur, Kampung Melango Baru sebagai bahan kajian. Yang berikut ialah judul lima buah seni kata lagi dikir al-Burdah yang dianalisis iaitu "Asam Gading”, "Aduhai Pengantin Baru”, "Selamat Pengantin Baru", "Gendang Berbunyi" dan "Pengantin Berinai". Selain seni kata lagu "Selamat Pengantin Baru" yang ditulis oleh Yusuf Ahmad Sabri dan Azahari Ahmad yang asalnya dinyanyikan oleh kumpulan nasyid kontemporari yang popular di Malaysia sekitar hujung tahun 1990-an, iaitu Hijjaz), seni kata lagu yang lain ditulis atas nama Pertubuhan An-Nur, Kampung Melango Baru. Menurut Tuan Haji Mohamed Usup bin Rahman, lagu ini termasuk seni katanya diberikan oleh Abg. Rosli bin Abg. Anyut yang berasal dari Sri Aman dan menjadi tenaga pengajar dikir al-Burdah bagi anggota Pertubuhan An-Nur, Kampung Melango Baru (Wawancara dengan Tuan Haji Mohamed Usup bin Rahman bertarikh 14 Julai 2017).

\section{FORMALISME: SATU KAEDAH ANALISIS}

Kajian ini mengguna pakai pendekatan analisis teks yang menjadikan seni kata lagu dikir al-Burdah sebagai bahan atau teks yang dianalisis. Pendekatan tersebut membolehkan kajian ini menerapkan Teori Formalisme yang kerap digunakan dalam pengkajian sastera. Dalam bidang kesusasteraan, Formalisme lazimnya ditangani sebagai satu kaedah dalam kritikan teks. Nama "formalisme" lebih diguna pakai dalam kalangan pengkritik sastera di Britain. Pengkritik sastera di Amerika Syarikat pula menyebutnya sebagai "Kritikan Baharu” (New Criticism) (Mana Sikana, 2012, p. 2). Teori Formalisme dikatakan tercetus di Rusia pada awal abad ke-20 Masihi, disebabkan pandangan para pengkritik yang berpendapat bahawa kritikan terhadap teks sastera mesti memberikan fokus terhadap teks sastera itu sendirinya (Jefferson, 1988, pp. 36-40). Fokus yang sedemikian dengan sendirinya membolehkan kajian untuk meneliti aspek yang menunjangi struktur sesebuah teks sastera (Ungku Maimunah, 2010, p. 183). Aspek 
sastera ini antaranya merangkumi mesej, tema, persoalan, dan gaya bahasa. Dengan mengambil kira fokus serta penekanan Formalisme, kajian ini akan menganalisis bahan kajian berdasarkan tiga prosedur berikut.

Pertama, analisis aspek struktur seni kata lagu dikir al-Burdah. Prosedur ini menuntut pengenalpastian jumlah rangkap, jumlah baris dalam rangkap, dan jumlah perkataan dalam setiap baris. Turut dikenal pasti ialah rima akhir setiap rangkap. Prosedur ini penting bagi memahami bentuk yang menampung mesej yang terkandung dalam seni kata lagu dikir al-Burdah yang dianalisis.

Kedua, analisis aspek isi kandungan seni kata lagu dikir al-Burdah. Prosedur ini menuntut penelitian terhadap perkataan yang mengisi setiap baris dalam setiap rangkap. Prosedur ini penting bagi memahami mesej yang terkandung dalam seni kata lagu dikir al-Burdah yang dikaji. Istilah "mesej" dalam konteks analisis ini merujuk aspek pengajaran atau pesanan yang disampaikan. Dalam konteks bahan kajian bersifat tekstual seperti seni kata lagu dikir al-Burdah, aspek "mesej" dapat difahami dengan meneliti maksud yang terkandung dalam perkataan yang mengisi baris serta rangkap dalam seni kata lagu dikir al-Burdah yang dikaji.

Ketiga, analisis kesejajaran mesej dalam seni kata dikir al-Burdah dengan ajaran Islam. Prosedur ini menuntut penilaian terhadap mesej yang terkandung dalam seni kata lagu dikir al-Burdah berdasarkan ajaran Islam, seperti yang terkandung dalam al-Quran dan Hadis, iaitu dua sumber ilmu yang dianggap paling berautoriti dalam tradisi keilmuan Islam. Untuk itu, analisis akan memanfaatkan dua kitab tafsir al-Quran, iaitu Tafsir al-Azhar karangan Haji Abdul Malik Abdul Karim Amrullah r.h. (lebih dikenali dengan nama Hamka r.h.) yang merupakan seorang ulama Melayu yang terkenal, dan Tafsir Ibnu Katsier yang telah diterjemahkan dalam bahasa Indonesia oleh H. Salim Bahreisy dan H. Said Bahreisy. Turut dimanfaatkan ialah kitab berjudul Riyadhus Shalihin karangan Imam Nawawi r.h. yang telah diterjemahkan dalam bahasa Indonesia oleh Zenal Mutaqin dkk. Ketiga-tiga prosedur analisis kaedah kritikan Formalisme dijangka dapat membantu kajian ini untuk merealisasikan objektif kajian yang telah digariskan.

\section{DIKIR AL-BURDAH SEBAGAI SEBUAH GENRE SASTERA}

Menurut Harun Mat Piah (1989, p. 526), "dikir" dalam bahasa Melayu berasal daripada bahasa Arab, iaitu zikir yang bermaksud doa atau pujipujian kepada Allah SWT yang dilafazkan secara berlagu atau tidak, atau dengan cara berulang-ulang seperti dalam perayaan Maulid Nabi, iaitu 
meraikan hari kelahiran Nabi Muhammad SAW. Abdul Halim (2006, p. 64) pula menjelaskan bahawa "dikir" dikategorikan dalam puisi tumpang. Puisi tumpang ialah nama yang diberikan kepada karya puisi Melayu tradisional yang tidak mempunyai ciri khusus, melainkan menumpang pada bentuk puisi yang lain. Meskipun menumpang bentuk puisi yang lain, puisi ini mendukung isi atau kandungan yang berbeza dengan puisi yang ditumpanginya. Menurut Abdul Halim lagi, dikir juga merupakan sebuah genre puisi Melayu yang menumpang pada bentuk puisi Arab atau Parsi. Kewujudan genre ini dianggap melambangkan keunikan masyarakat Melayu zaman lampau yang memiliki daya kreativiti dan imaginasi yang tinggi, di samping berkebolehan mengolah persoalan hidup mereka berlandaskan tradisi sastera pelbagai sumber (Abdul Halim, 2006, p. 64).

Dalam masyarakat Melayu, amalan "berzikir" lazimnya merujuk bacaan yang dilakukan oleh orang Islam dengan menyebutnya secara berulang-ulang dalam kiraan tertentu nama Allah SWT atau ungkapan pujian ke hadrat Allah SWT. Antara ungkapan tersebut termasuklah Allah, Subhanallah, Alhamdulillah, Lailahaillallah dan Allahuakbar (Harun Mat Piah, 1989, p. 526). Dalam amalan masyarakat Melayu, "berzikir" yang bertujuan mengingati Allah SWT dilakukan sama ada secara sendirian atau berkumpulan, terutamanya ketika selesai melaksanakan solat atau dalam majlis tahlil. Dengan tujuan itu, amalan "berzikir" dianggap sebagai ibadat manusia kepada Allah SWT. Akan tetapi, "dikir" yang menjadi fokus kajian ini merujuk persembahan kesenian yang diamalkan dalam masyarakat. Dalam persembahan "dikir", pujian ke hadrat Allah SWT dan Nabi Muhammad SAW. dialunkan dengan iringan bunyi-bunyian seperti kompang atau rebana, selain gerakan tertentu oleh para pengalun "dikir" secara berkumpulan (Mohd. Taib, 1979 p. 102).

Dalam kalangan masyarakat Melayu, persembahan "dikir" diamalkan di beberapa negeri dengan nama yang berbeza, antaranya termasuklah dikir rebana di Pahang, dikir Perak di Perak, dikir Minang di kalangan orang Minangkabau, dikir badau di Terengganu, dikir Nabi Allah di Negeri Sembilan, dikir berdah di Selangor dan Pahang, dan dikir al-Burdah di Sarawak (Harun Mat Piah, 1989, p. 528). Kelazimannya, "dikir" dipersembahkan dalam majlis atau upacara tertentu antara seperti sambutan Maulidur Rasul, majlis perkahwinan, khatam al-Quran, dan naik buaian atau berendoi (Harun Mat Piah, 1989 p. 547).

"Dikir" disampaikan melalui tradisi lisan, iaitu alunan suara yang dipersembahkan secara berkumpulan. Oleh sebab medium penyebarannya 
(secara lisan), dalam pengkajian sastera genre "dikir" rata-rata digolongkan sebagai warisan kesusasteraan rakyat (Harun Jaafar, 2002 p. 48). Sebagai sebuah genre sastera, "dikir" digolongkan sebagai puisi bebas kerana tidak terikat dengan bentuk tertentu seperti jumlah rangkap, baris, perkataan dan suku kata, atau rima akhir pada setiap baris. Menurut Harun Mat Piah (1989 p. 528), "dikir" lazimnya mengandungi ungkapan yang bebas dari segi rangkap, baris, perkataan, dan suku kata termasuk rima akhir. "Dikir" dikatakan mengambil bentuk genre puisi yang lain seperti pantun, syair, mantera, nazam dan qasidah. Menurut Abdul Halim (2006 p. 122). Genre "dikir" antaranya dicirikan dengan kehadiran ungkapan berupa puji-pujian ke hadrat Allah SWT serta selawat serta salam atas junjungan besar Nabi Muhammad SAW. Ungkapan ini mengisi baris-baris ayat yang membentuk sebuah rangkap tersendiri, yang adakalanya diulang-ulang beberapa kali (Abdul Halim, 2006, p.122).

Dari segi fungsinya, persembahan "dikir" dianggap berperanan sebagai wadah pengajaran yang dapat mendidik masyarakat. Fungsi ini dikenal pasti berdasarkan isi kandungan genre "dikir" yang rata-rata menyeru manusia untuk berbuat kebaikan serta menjauhi kejahatan seperti yang digariskan dalam ajaran Islam. Sehubungan itu, "dikir" turut dianggap memainkan peranan dalam mengejapkan nilai yang menjadi pegangan masyarakat (Harun Jaafar, 2002 p. 48). Selain itu, “dikir" turut dikatakan berperanan sebagai wadah hiburan kepada masyarakat. Fungsi ini dikenal pasti berdasarkan persembahan yang lazimnya mengisi acara keraian seperti majlis sambutan para pembesar masyarakat, atau majlis perkahwinan (Harun Jaafar, 2002, p. 48).

Perkataan "burdah", dalam dikir al-Burdah, dikaitkan dengan kain bulu yang dipakai oleh masyarakat Arab. Nabi Muhammad SAW diceritakan pernah menghadiahkan burdah (kain bulu) milik baginda kepada Ka'ab bin Zuhayr, seorang penyair Arab-Jahiliyah (Stetkevych, 2010 p. 63) yang mengungkapkan syair yang dikenali sebagai Banat Su'ad. Kegiatan dikir al-Burdah di Sarawak turut dikaitkan dengan tradisi al-Qasidah al-Mimiyah yang dipelopori oleh Imam al-Busiri @ al-Busairi (608-696 H.), seorang ulama tasawuf Mesir (Raslie, 1988 p. 132). Menurut Hj. Muhammad Bukhari (1994, p. 128), pengaruh tradisi al-Qasidah al-Mimiyah tersebar luas dalam kalangan masyarakat Islam di seluruh dunia termasuk masyarakat Melayu di Sarawak yang menyebutnya sebagai dikir al-Burdah. Secara keseluruhannya, dapat disimpulkan bahawa dikir al-Burdah dalam kalangan masyarakat Melayu di Sarawak rata-rata merujuk puisi yang mengandungi puji-pujian kepada Allah SWT serta selawat, dan salam atas junjungan besar 
Nabi Muhammad SAW. Puisi ini dialunkan secara berkumpulan dengan gaya persembahan tertentu, iaitu diiringi bunyi-bunyian daripada paluan gendang atau rebana, selain gerakan tertentu.

\section{ANALISIS SENI KATA LAGU DIKIR AL-BURDAH BERKAITAN PERKAHWINAN}

Analisis ini dimulakan dengan meneliti seni kata lagu berjudul "Asam Gading”. Dari segi struktur, seni kata ini mengandungi tujuh rangkap. Satu rangkap, iaitu rangkap pertama mengandungi dua baris, manakala enam rangkap lagi, iaitu rangkap kedua hingga keenam mempunyai empat baris. Setiap baris pula mengandungi tiga hingga lima perkataan, kecuali rangkap pertama yang hanya terdiri daripada satu perkataan sebaris. Empat rangkap seni kata ini menggunakan rima akhir a/a/a/a, manakala tiga rangkap lagi menggunakan rima akhir $\mathrm{a} / \mathrm{b} / \mathrm{a} / \mathrm{b}$.

Analisis ini mendapati bahawa seni kata ini mengutarakan mesej tentang kerukunan rumah tangga. Pengutaraan mesej ini jelas pada pengertian yang terkandung pada seni kata lagu ini. Rangkap pertama; baris pertama dan kedua seni kata dikir ini dimulai dengan kalimat dalam bahasa Arab yang berbunyi, "Lailahaillallah/ Muhammadurrasulullah", yang antara lain bermaksud, "Tiada Tuhan yang berhak disembah melainkan Allah SWT dan Nabi Muhammad SAW ialah pesuruh Allah SWT." Kalimat ini merupakan pengakuan terhadap kewujudan Allah SWT yang di sisi agama Islam dianggap sebagai satu-satunya Tuhan atau Pencipta sekalian alam yang wajib untuk diyakini serta disembah. Kalimah ini juga merangkumi perakuan terhadap kedudukan Nabi Muhammad SAW sebagai seorang "Rasul", iaitu utusan agung pilihan Allah SWT yang diamanahkan dengan tugas untuk menyampaikan wahyu-Nya kepada seluruh umat manusia.

Rangkap kedua; baris pertama hingga keempat pula menghadirkan nasihat agar pasangan suami isteri sentiasa bersikap terbuka dan saling bertolak ansur antara satu sama lain. Sikap ini penting kerana perkahwinan dalam seni kata lagu ini dipersepsikan sebagai perkongsian hidup sepanjang hayat. Sikap terbuka dan saling bertoleransi dapat menjadikan sesebuah rumah tangga yang dibina itu kekal bahagia, seperti dalam petikan berikut, "Wahai pengantin yang budiman/ Suami isteri sama sefahaman/ Berkongsi hidup sepanjang zaman/ Semoga hidupmu berkekalan".

Rangkap ketiga; baris pertama hingga keempat menghadirkan nasihat supaya pasangan suami isteri bertolak ansur dalam soal wang ringgit atau perbelanjaan rumah tangga. Rangkap ini turut mengingatkan bahawa 
kegembiraan terletak pada kesihatan serta kesejahteraan. Dengan kesihatan yang sempurna, diharapkan pasangan suami isteri cepat dianugerahkan zuriat, seperti dalam petikan berikut, "Kedua pengantin hati gembira/ Wang dan ringgit jangan dikira/ Asalkan sihat selamat sejahtera/ Hingga mendapat cahaya mata".

Rangkap keempat; baris pertama hingga baris keempat menjelaskan bahawa majlis perkahwinan merupakan satu rahmat kurniaan Allah SWT Rangkap ini diakhiri dengan doa supaya ikatan yang dibina sentiasa dilindungi dan diredai oleh Allah SWT sepanjang hayat, seperti dalam petikan berikut, "Hajat di hati tunailah sudah/ Diijabkabulkan penuh beradat/ Suatu rahmat dikurniakan Allah/ Semoga selamat dunia dan akhirat".

Rangkap kelima; baris pertama hingga baris kelima pula menghadirkan doa untuk semua supaya Allah SWT memelihara keimanan atau keyakinan kepada-Nya, yang disusuli dengan nasihat agar manusia terus melaksanakan amal soleh atau perbuatan yang baik di sisi Islam. Seterusnya, pesanan supaya manusia melaksanakan Rukun Islam yang lima, iaitu mengucapkan dua kalimah syahadah, mendirikan solat lima waktu sehari semalam, berpuasa pada bulan Ramadan, membayar zakat serta mengerjakan haji di Mekah, seperti dalam petikan berikut, "Ya Allah Tuhan Yang Esa/ Tetapkanlah iman kami semua/ Amal kebajikan jangan dilupa/ Rukun Islam hendaklah dilaksanakan".

Rangkap keenam; baris pertama hingga keempat menghadirkan lafaz kesyukuran serta doa semoga Allah SWT memberkati majlis perkahwinan tersebut serta dikurniakan kesejahteraan hidup hingga ke akhir hayat, seperti dalam petikan berikut, "Alhamdulillah syukur nikmat/ Mohon kurnia kepada Tuhan/ Mudah-mudahan mendapat rahmat/ Sejahtera hingga ke akhir zaman”.

Rangkap ketujuh, iaitu rangkap yang terakhir; baris pertama hingga baris keempat diakhiri dengan doa serta harapan agar dipertemukan lagi pada persembahan yang akan datang, seperti dalam petikan berikut, "Wahai pendengar yang budiman/ Kami bermohon mengundur diri/ zikir al-Burdah kami persembahkan/ Panjang umur berjumpa lagi”.

Dengan maksud yang terkandung dalam tujuh rangkap di atas, analisis ini mendapati bahawa seni kata lagu dikir berjudul "Asam Gading" mengutarakan mesej tentang kerukunan rumah tangga.

Seterusnya, analisis ini mendapati bahawa mesej yang sama turut diutarakan dalam sebuah lagi seni kata lagu dikir yang berjudul "Aduhai Pengantin Baru". Dari segi struktur, seni kata ini mengandungi lima rangkap. Setiap rangkap mengandungi enam baris, kecuali rangkap kedua yang terdiri 
daripada tujuh baris. Setiap baris pula mengandungi satu hingga tujuh perkataan. Dua rangkap seni kata ini menggunakan rima akhir $\mathrm{a} / \mathrm{b} / \mathrm{a} / \mathrm{b} / \mathrm{a} / \mathrm{b}$, satu rangkap lagi (rangkap ketiga) menggunakan rima akhir a/b/a/a/b/a. Dua rangkap lagi menggunakan rima akhir bebas yang tidak terikat dengan pola tertentu.

Rangkap pertama; baris pertama seni kata dikir ini dimulai dengan kalimat dalam bahasa Arab yang berbunyi, "Bismillah", yang antara lain bermaksud, "Dengan Nama Allah" yang menandakan bahawa bermulanya upacara tepung tawar pasangan mempelai", disusuli pula dengan ucapan selamat pengantin baru yang ditujukan khusus untuk pasangan mempelai yang diraikan di atas pelamin. Turut disampaikan ialah harapan semoga pasangan mempelai sentiasa bahagia selamanya, seperti dalam petikan berikut, "Awal Bismillah awal Bismillah menepek inai/ Inai ditepek aduhai sayang/ Inai ditepek di tapak tangan/ Mari berdoa mari berdoa beramai-ramai/ Supaya pengantin aduhai sayang/ Supaya pengantin di dalamlah aman".

Rangkap kedua; baris pertama hingga ketujuh pula memuji pasangan mempelai yang sedang bersanding. Puji-pujian ini antara lain menyebut tentang kecantikan serta seri pasangan pengantin diumpamakan pasangan raja, seperti dalam petikan berikut, "Selamat bersanding selamat bersanding pengantin jauhari/ Di atas takhta aduhai pengantin/ Di atas takhta kerajaan sehari/ Cantiklah molek cantiklah molek indah berseri/ Gilang-gemilang aduhai pengantin/ Gilang-gemilang intan baiduri”.

Rangkap ketiga; baris pertama hingga keenam memberikan nasihat supaya pasangan suami isteri sentiasa berbuat baik antara satu sama lain, bergurau senda dan sentiasa menjaga tutur kata agar rumah tangga yang dibina sentiasa bahagia. Pengantin diingatkan tentang pentingnya kesetiaan dan kesatuan dalam hubungan suami isteri. Peringatan terkandung dalam ungkapan "jangan bercabang" yang boleh membawa maksud jangan berpecah atau berpisah, seperti dalam petikan berikut, "Berpakatlah baik berpakatlah baik setiap hari/ Bersuka ria aduhai pengantin/ Bersuka ria apatah lagi/ Jangan bercabang/ jangan bercabang ke sana sini/ Akhir kecewa aduhai pengantin/ Akhir kecewa suami isteri”.

Rangkap keempat; baris pertama hingga keenam pula menghadirkan nasihat supaya pasangan suami isteri sentiasa memelihara tutur kata. Kesilapan dalam tutur kata dapat mencetuskan pertelingkahan dalam perhubungan serta menimbulkan masalah dalam rumah tangga yang terbina, seperti dalam petikan berikut, "Terlajak kapal terlajak kapal dapat diundur/ Terlajak kata aduhai sayang/ Terlajak kata buruk padahnya/ Tuturlah kata tuturlah kata 
hendak teratur/ Supaya tidak aduhai sayang/ Supaya tidak menjadi bala".

Rangkap kelima, iaitu rangkap terakhir; baris pertama hingga baris keenam diakhiri dengan harapan semoga ikatan perkahwinan yang terbina antara pasangan mempelai kekal hingga ke akhir hayat, selain mendapat perlindungan serta rahmat daripada Allah SWT. Perkahwinan dalam seni kata lagu ini dipersepsikan sebagai satu perhubungan yang suci dan abadi, seperti dalam petikan berikut, "Kami berdoa kami berdoa pada Ilahi/ Semoga pengantin aduhai sayang/ Semoga pengantin kekal abadi".

Dengan maksud yang terkandung dalam lima rangkap di atas, analisis ini mendapati bahawa seni kata lagu dikir berjudul "Aduhai Pengantin Baru" mengutarakan mesej tentang kerukunan rumah tangga.

Seterusnya, analisis ini mendapati bahawa mesej yang sama turut diutarakan dalam satu lagi seni kata lagu dikir yang berjudul "Selamat Pengantin Baru". Dari segi struktur, seni kata ini mengandungi enam rangkap. Tiga rangkap, iaitu rangkap pertama, kedua dan kelima mengandungi empat baris, manakala satu rangkap lagi, iaitu rangkap ketiga mempunyai enam baris. Selain itu, dua rangkap lagi, iaitu rangkap keempat dan keenam masingmasing hanya mempunyai satu baris. Setiap baris pula mengandungi tiga hingga enam perkataan. Secara keseluruhannya, seni kata ini menggunakan rima akhir bebas yang tidak terikat dengan pola tertentu.

Pengutaraan mesej tentang kerukunan rumah tangga jelas pada pengertian yang terkandung pada judul lagu, iaitu "Selamat Pengantin Baru". Dalam Kamus Dewan (2010, pp. 1419 \& 1172), maksud perkataan "selamat" dijelaskan seperti berikut, "... ucapan atau doa dengan harapan supaya sejahtera (terhindar daripada segala bencana, sampai hajat dll)". Maksud perkataan "pengantin baru" pula dijelaskan seperti berikut, "mempelai atau orang yang sedang menjalani istiadat perkahwinan". Dengan pengertian ini, dapat dikatakan bahawa ungkapan "Selamat Pengantin Baru" yang dijadikan sebagai judul dapat memberikan pengertian bahawa seni kata lagu bakal berlegar tentang doa dan harapan supaya pasangan mempelai hidup dalam kesejahteraan. Pemahaman ini dapat diperkukuh dengan pengertian yang terkandung dalam setiap rangkap seni kata lagu.

Rangkap pertama; baris pertama hingga keempat seni kata ini dimulai dengan doa supaya Allah SWT merestui ikatan perkahwinan yang digambarkan sebagai penyatuan antara dua hati. Perkahwinan dalam seni kata lagu ini turut dipersepsikan sebagai permulaan kepada pelayaran bahtera kehidupan berumah tangga, seperti dalam petikan berikut, "Bila dua hati 
dah terjalin/ Selamatlah pengantin kami doakan/ Moga reda Allah bersinar selalu/ Tanda bermula bahtera hidup". Rangkap pertama ini kemudiannya diulang sepenuhnya dalam rangkap kelima.

Rangkap kedua; baris pertama hingga keempat pula menghadirkan nasihat supaya pasangan suami isteri sentiasa tabah dan sabar dalam mengharungi kehidupan alam rumah tangga. Sifat sabar itu dianggap penting kerana kehidupan berumah tangga dikatakan tidak terlepas daripada ujian dan ada pasang surutnya. Oleh itu, pasangan pengantin dinasihatkan supaya tidak menuruti hawa nafsu dan bersifat pemaaf, seperti dalam petikan berikut, "Dalam melayari bahtera rumah tangga/ Ada masa tenang dan masa gelisah/ Jangan nafsu diikut melulu/ Sabar dan kemaafan itu perlu".

Rangkap ketiga; baris pertama hingga keenam pula menghadirkan nasihat supaya pasangan suami isteri saling menjalankan tanggungjawab dengan amanah. Suami dianggap sebagai ketua, manakala isteri pula dianggap sebagai pembantu. Oleh itu, kedua-duanya diseru supaya sentiasa bersatu dalam mengharungi liku kehidupan berumah tangga. Rangkap ini diakhiri dengan doa supaya rumah tangga yang dibina berkekalan, seperti dalam petikan berikut, "Beginilah resam manusia/ Tak lari dari ketentuan Ilahi/ Suami ketua isteri pembantu/ Melangkah hidup saling berpadu/ Susah dan senang hadapi bersama/ Moga kekal ke anak cucu”.

Rangkap keempat pula mengandungi satu baris ayat yang berupa doa supaya rumah tangga yang dibina berkekalan hingga ke syurga, iaitu "Moga kekal hingga ke syurga". Ayat ini hadir sebagai penegasan terhadap isi dikir yang telah disampaikan pada rangkap sebelumnya.

Rangkap kelima seperti yang telah dinyatakan di atas, mengulangi semula sepenuhnya rangkap pertama, seperti dalam petikan berikut, "Bila dua hati dah terjalin/ Selamatlah pengantin kami doakan/ Moga reda Allah bersinar selalu/ Tanda bermula bahtera hidup". Rangkap ini disusuli dengan rangkap keenam, iaitu rangkap terakhir yang menghadirkan ungkapan "Selamat Pengantin Baru" yang juga merupakan judul seni kata lagu. Ungkapan ini hadir sebagai penegasan terhadap judul dikir yang disampaikan.

Dengan maksud yang terkandung dalam enam rangkap di atas, analisis ini mendapati bahawa seni kata lagu dikir berjudul "Selamat Pengantin Baru" mengutarakan mesej tentang kerukunan rumah tangga.

Seterusnya, analisis ini mendapati bahawa mesej yang sama turut diutarakan dalam sebuah lagi seni kata lagu dikir yang berjudul "Gendang Berbunyi”. Dari segi struktur, seni kata dikir ini mengandungi empat rangkap. Satu rangkap, iaitu rangkap keempat mengandungi 12 baris, manakala tiga 
rangkap lagi, iaitu rangkap pertama hingga ketiga mempunyai lapan baris. Setiap baris pula mengandungi tiga hingga lima perkataan. Dua rangkap menggunakan rima akhir $\mathrm{a} / \mathrm{a} / \mathrm{a} / \mathrm{a} / \mathrm{a} / \mathrm{a} / \mathrm{a} / \mathrm{a}$, manakala dua rangkap menggunakan rima akhir bebas yang tidak terikat dengan pola tertentu.

Pengutaraan mesej tentang kerukunan rumah tangga jelas pada pengertian yang terkandung pada seni kata lagu ini. Rangkap pertama; baris pertama seni kata dimulai dengan ucapan selamat pengantin baru yang ditujukan khas kepada pasangan mempelai yang sedang diraikan. Baris pertama diikuti dengan baris kedua hingga keempat memerikan tentang paluan gendang diiringi alunan dikir yang dipersembahkan untuk meraikan mempelai, serta para jemputan yang hadir bagi memeriahkan majlis perkahwinan. Baris kelima hingga kelapan pula menggambarkan juadah yang disajikan, yang diikuti dengan harapan supaya para hadirin bergembira serta menikmati juadah yang disediakan. Seni kata lagu ini cenderung menggambarkan kemeriahan suasana dalam majlis perkahwinan, seperti dalam petikan berikut, "Ucap selamat pengantin baru/ Bunyi gendang bertalu-talu/ Diiringi suara merdu/ Sorak-sorai sambil berlagu/ Tetamu datang dijamu/ Makan minum sedang menunggu/ Harap tuan janganlah jemu/ Sambil bersorak, selera dijamu".

Rangkap kedua; baris pertama dan kedua memuji pasangan mempelai yang digambarkan sama cantik dan sama padan. Baris ketiga dan keempat mengandungi pesan supaya mereka sentiasa tabah serta sabar dalam menempuh cabaran hidup berumah tangga. Perkahwinan dalam seni kata lagu ini digambarkan sebagai kehidupan berumah tangga yang tidak terlepas daripada cabaran, dan menuntut ketabahan serta kesabaran. Baris kelima hingga kelapan kembali memberikan puji-pujian kepada pasangan mempelai akan kecantikan rupa paras, tingkah laku yang diumpamakan seperti batu permata, seperti dalam petikan berikut, "Duduk bersanding dua arjuna/ Bagai pinang dibelah dua/ Walau berjuta bencana tiba/ Tabah hati banyak bersabar/ Sama cantik dua sejoli/ Bersopan santun merendah diri/ Senyum simpul berseri-seri/ Bagai permata intan berduri".

Rangkap ketiga; baris pertama dan kedua sekali lagi memerikan suasana majlis perkahwinan yang dimeriahkan dengan paluan gendang dan alunan zikir yang memuji Allah SWT, yang diikuti dengan baris ketiga dan keempat yang memohon doa kepada Allah SWT supaya rumah tangga yang dibina berkekalan. Baris kelima hingga kelapan mengulangi puji-pujian terhadap rupa paras pasangan pengantin yang direnjis air mawar yang harum, seperti dalam petikan ini, "Gendang dipalu memecah sunyi/ Suara zikir turut 
memuji/ Kami berdoa pada Ilahi/ Semoga hidup kekal abadi/ Direnjis mawar mewangi/ Atas kepala, tangan dan kaki/ Si teruna tampan sekali/ Si jelita cantik berseri”.

Rangkap keempat, iaitu yang terakhir; baris pertama hingga ketiga turut memerikan suasana majlis perkahwinan yang meriah dengan kehadiran sahabat handai yang menyaksikan upacara persandingan kedua-dua mempelai. Baris keempat hingga kelapan mengungkapkan perihal ikatan perkahwinan yang terjalin atas persetujuan serta perasaan cinta antara pasangan mempelai, seperti dalam petikan berikut, "Di majlis yang indah permai/ Disaksikan sahabat handai/ Pengantin baru duduk bersanding/ Bagai raja dan pengiring/ Setuju satu dan lain/ Baru dapat kasih terjalin/ Umur tak jadi perkara/ Kalau hati dah sama suka". Seterusnya baris kesembilan hingga baris kedua belas yang merupakan ucapan sebagai penutup persembahan. Ucapan daripada kumpulan dikir al-Burdah mengandungi permohonan untuk menamatkan persembahan, meminta maaf atas segala kekhilafan, selain pesanan supaya mengundang mereka lagi untuk membuat persembahan, seperti dalam petikan berikut, "Sebelum kami mengundur diri/ Tersalah kata harap dimaafi/ Kalau ada jemputan lagi/ Jangan lupa kumpulan kami”.

Dengan maksud yang terkandung dalam empat rangkap di atas, analisis ini mendapati bahawa seni kata lagu dikir berjudul "Gendang Berbunyi" mengutarakan mesej tentang kerukunan rumah tangga.

Analisis ini mendapati bahawa mesej yang sama turut diutarakan dalam sebuah lagi seni kata lagu dikir yang berjudul "Pengantin Berinai". Dari segi struktur, seni kata ini mengandungi empat rangkap. Setiap rangkap mengandungi lima baris. Setiap baris pula mengandungi lima hingga enam perkataan. Semua rangkap menggunakan rima akhir bebas yang tidak terikat dengan pola tertentu.

Pengutaraan mesej tentang kerukunan rumah tangga jelas pada pengertian yang terkandung dalam seni kata lagu ini. Rangkap pertama; baris pertama hingga kelima menggambarkan suasana majlis perkahwinan yang dimeriahkan dengan paluan gendang serta para hadirin yang bergembira kerana menyambut kedatangan serta persandingan pengantin, seperti dalam petikan berikut, "Gendang dipalu/ Orang pun bersorak riuh dan ramai/ Itulah tanda pengantin datang/ Lalu duduk bersanding/ Dibaling bunga rampai".

Rangkap kedua; baris pertama hingga baris kelima pula menggambarkan kecantikan rupa paras pengantin perempuan, selain kegembiraan yang terpancar di wajahnya ketika menunggu ketibaan pengantin lelaki, seperti yang terkandung dalam rangkap dikir yang diturunkan dalam petikan ini, "Duduk tersenyum/ Anak dara jelita tersimpul menanti/ Jarinya lentik/ 
Merah berinai rambut mayang mengurai/ Wajah berseri-seri”.

Rangkap ketiga; baris pertama dan kedua memerikan detik persandingan bermula dengan kedatangan pengantin lelaki. Baris ketiga hingga kelima berupa puji-pujian kepada pasangan pengantin yang sedang bersanding yang dikatakan sama cantik dan sama padan yang diumpamakan bagai pinang dibelah dua, seperti dalam petikan berikut, "Masa pun telah tiba/ Lalu bersanding pengantin arjuna/ Amboi mak bak pinang dibelah dua/ Duduk sama rendah/ Tegak diukur sama".

Rangkap keempat, iaitu rangkap terakhir; baris pertama hingga kelima mengandungi ucapan selamat kepada pasangan mempelai yang diharapkan sentiasa bersatu dalam mengharungi kehidupan berumah tangga. Dapat dikatakan bahawa perkahwinan dalam seni kata lagu ini cenderung digambarkan sebagai kehidupan berumah tangga yang menuntut persefahaman antara pasangan suami isteri. Ucapan selamat ini didahului dengan dua baris awal yang memerikan upacara persandingan yang diserikan dengan adat merenjis air mawar kepada pasangan mempelai, seperti dalam petikan berikut, "Renjis direnjis renjis/ Lalu direnjis dengan air mawar/ Selamat dua pengantin baru/ Bersama berpadu/ Menempuh alam baru".

Dengan maksud yang terkandung dalam empat rangkap di atas, analisis ini mendapati bahawa seni kata lagu dikir berjudul "Pengantin Berinai" mengutarakan mesej tentang kerukunan rumah tangga.

Kesemua seni kata lagu dikir al-Burdah yang dikaji didapati mengutarakan mesej tentang kerukunan rumah tangga. Seterusnya, analisis ini mendapati bahawa mesej kerukunan rumah tangga yang digarap itu seiring dengan ajaran Islam, seperti yang terkandung dalam al-Quran dan hadis. Kepentingan kerukunan rumah tangga ada dinyatakan dalam al-Quran, Surah Ar-Ruum, ayat 21 yang antara lain bermaksud:

Dan setengah daripada tanda-tanda kebesaran-Nya bahwa Dia ciptakan untuk kamu dari dirimu sendiri akan isteri-isteri, agar tenteramlah kamu kepadanya. Dan Dia jadikan di antara kamu cinta dan kasih sayang. Sesungguhnya pada yang demikian adalah tandatanda bagi kamu yang berfikir.

(Haji Abdul Malik, 1984a, p. 78).

Merujuk ayat al-Quran di atas pula, Haji Abdul Malik Abdul Karim Amrullah r.h. (atau lebih dikenali sebagai Hamka r.h.) (seterusnya Haji Abdul Malik r.h.) dalam Tafsir al-Azhar (1984a) antara lain menjelaskan bahawa 
manusia itu diciptakan dengan tabiinya untuk saling berpasang-pasangan antara lelaki dengan perempuan, yang melaluinya keturunan manusia dapat berkembang biak. Untuk itu, manusia dikurniakan dengan perasaan saling berkasih sayang antara pasangan suami isteri bagi membolehkan mereka hidup dalam keadaan tenteram serta rukun damai, seperti yang dijelaskan oleh beliau dalam petikan di bawah:

Dan Kami ciptakan kamu itu berpasang-pasangan”. Yaitu berlakilaki berperempuan, berjantan berbetina. Maka dipertemukanlah oleh Allah "jodoh" di antara kedua pihak si jantan dengan si betina, untuk melanjutkan tugas berkembang biak di muka bumi; "Agar tenteramlah kamu kepadanya". Artinya akan gelisahlah hidup kalau hanya seorang diri karena kesepian, terpencil tidak berteman. Lalu si laki-laki mencari-cari si perempuan sampai dapat dan si perempuan menunggu-nunggu si laki-laki sampai datang. Maka hidup pun dipadukanlah jadi satu. Karena hanya dengan perpaduan jadi satu itulah akan dapat langsung pembiakan manusia. "Dan Dia jadikan di antara kamu cinta dan kasih sayang". Cinta dan kasih sayang dengan sendirinya tumbuh. Pertama sebab positif selalu ingin menemui negatif, jantan mencari betina dan laki-laki inginkan perempuan. Segala sesuatu mencari timbalannya. Dan yang demikian tidaklah akan terjadi atau membawa hasil yang dimaksudkan, yaitu perkembangan-biak, kalau tidak dari yang sejenis.

(Haji Abdul Malik, 1984a, pp. 83-84).

Merujuk ayat al-Quran yang sama, Ibnu Katsier r.h. seorang ulama tafsir yang masyhur, dalam tafsir beliau menjelaskan bahawa Allah SWT telah menciptakan manusia terdiri daripada lelaki dan perempuan yang keduaduanya saling cenderung antara satu sama lain. Mereka juga dikurniakan perasaan kasih sayang yang membolehkan mereka hidup dalam keadaan yang tenteram dan aman, seperti pandangan Ibnu Katsier r.h. yang diterjemahkan oleh H. Salim Bahreisy dan H. Said Bahreisy (seterusnya H. Salim \& H. Said) seperti dalam petikan di bawah:

Dan sebagai tanda kesempurnaan hikmah-Nya, Allah menciptakan manusia terdiri atas dua jenis laki dan perempuan agar saling isimengisi keperluan hidup di dunia ini dan menjadikannya tenteram dengan adanya kasih sayang antara keduanya. Maka sesungguhnya 
pada yang demikian itu benar-benar terdapat tanda-tanda kekuasaan Allah Yang Maha Bijaksana, bagi orang-orang yang mahu berfikir.

(Ibnu Katsier, 1994, p. 232).

Seterusnya, soal tanggungjawab pasangan suami isteri yang dianggap penting dalam menjamin kerukunan sesebuah rumah tangga turut terkandung dalam al-Quran Surah An-Nisaa', ayat 34 yang bermaksud:

Laki-laki pemimpin atas perempuan-perempuan, lantaran Allah telah melebihkan sebahagian mereka atas yang sebahagian, dan dari sebab apa yang mereka belanjakan dari harta-benda mereka. Maka perempuan yang baik-baik ialah yang taat, memelihara hal-ehwal yang tersembunyi, dengan cara yang dipelihara Allah. Dan perempuanperempuan yang kamu takut kedurhakaan mereka, maka ajarilah mereka, dan pisahlah dari mereka pada tempat-tempat tidur, dan pukullah mereka. Tetapi jika mereka telah taat kepadamu, janganlah kamu cari-cari jalan buat menyusahkan mereka. Sesungguhnya Allah adalah Maha Tinggi, lagi Maha Besar.

(Haji Abdul Malik Abdul Karim Amrullah, 1984b, p. 57).

Merujuk ayat al-Quran di atas, Haji Abdul Malik Abdul Karim Amrullah r.h. (atau lebih dikenali sebagai Hamka r.h.) (seterusnya Haji Abdul Malik r.h.) dalam Tafsir Al-Azhar (1984b) antara lain menjelaskan bahawa Islam telah memperuntukkan tanggungjawab yang jelas antara suami dengan isteri dalam sesebuah rumah tangga. Dalam hal ini, suami memikul tanggungjawab untuk memimpin isteri. Menurut Haji Abdul Malik r.h. lagi, tanggungjawab ini ada kaitannya dengan tabii kaum lelaki yang diciptakan dengan kekuatan fizikal yang lebih berbanding perempuan, seperti yang dijelaskan oleh beliau dalam petikan yang dikutip di bawah:

Sebab laki-laki itulah yang memimpin perempuan, bukan perempuan yang memimpin laki-laki, dan bukan pula sama kedudukan .... Di dalam ayat ini tidak langsung datang perintah mengatakan wahai laki-laki, wajiblah kamu jadi pemimpin. Atau wahai perempuan, kamu mesti menerima pimpinan. Yang diterangkan lebih dahulu ialah kenyataan. Tidakpun ada perintah, namun kenyataannya memang laki-lakilah yang memimpin perempuan .... Diterangkan sebab yang pertama di dalam ayat, ialah lantaran Allah telah melebihkan 
sebahagian mereka, yaitu mereka laki-laki atas yang sebahagian, yaitu perempuan. Lebih dalam tenaga, lebih dalam kecerdasan, sebab itu lebih pula dalam tanggung jawab. Misalnya berdiri rumah tangga, ada bapak, ada istri dan ada anak, dengan sendirinya - meskipun tidak disuruh - laki-lakilah, yaitu si bapak yang menjadi pimpinan. Seibarat batang tubuh manusia, ada kepala, ada tangan dan kaki, ada perut. Semuanya itu penting, tetapi yang kepala tetap kepala.

(Haji Abdul Malik, 1984b: 58-59).

Merujuk ayat al-Quran yang sama juga, Ibnu Katsier r.h. dalam tafsir beliau menjelaskan bahawa tanggungjawab untuk memimpin rumah tangga terletak di bahu suami kerana mereka mempunyai kelebihan jasmani dan akal fikiran, berbanding isteri. Menurut Ibnu Katsier r.h. lagi, sebagai seorang pemimpin, sekiranya seseorang suami menunaikan tanggungjawabnya mengikut ajaran Islam, dia wajib dipatuhi oleh isterinya, seperti pandangan Ibnu Katsier yang diterjemahkan oleh H. Salim \& H. Said seperti dalam petikan di bawah:

Selain kelebihan jasmani dan mental pihak lelaki di atas wanita yang menjadi pembawaan fitrah, juga kerana pihak lelaki berkewajiban menafkahkan hartanya untuk kepentingan hidup pihak wanita serta untuk memenuhi keperluan lain seperti maskawin dan beban-beban keuangan yang diwajibkan oleh Allah kepadanya menurut al-Qur'an dan sunnah Nabi-Nya SAW. maka dengan kelebihan-kelebihan itu patutlah pihak pria menjadi pemimpin dan wali atas pihak wanita .... Allah berfirman selanjutnya bahwa perempuan-perempuan yang soleh, ialah yang taat kepada Allah dan taat kepada suami-suaminya, memelihara dirinya dan harta suaminya di balik pembelakangan sang suami, oleh karena Allah telah memelihara mereka.

(Ibnu Katsier, 1988, pp. 387-388)

Analisis ini juga mendapati bahawa soal pentingnya kerukunan rumah tangga turut dinyatakan dalam sebuah hadis yang diriwayatkan oleh Bukhari r.h. dan Muslim r.h., yang antara lain bermaksud:

Dari Abu Mas'ud Al-Badriy r.a., dari Nabi SAW., beliau bersabda:

"Apabila seseorang menafkahkan harta untuk keperluan keluarganya 
dan hanya berharap mendapat pahala, maka itu akan dicatat sebagai sedekah baginya".

(Imam Nawawi, 2010, p. 125).

Dalam sebuah hadis lain yang diriwayatkan oleh Bukhari r.h. dan Muslim r.h., Rasulullah SAW. juga bersabda yang antara lain bermaksud:

Dari Ibnu Umar r.a., dari Nabi SAW., beliau bersabda: "Kalian adalah pemimpin dan diminta pertanggungjawaban atas kepemimpinan kalian. Seorang penguasa adalah pemimpin, seorang suami adalah seorang pemimpin seluruh keluarganya, demikian pula seorang isteri adalah pemimpin atas rumah suami dan anaknya. Kalian adalah pemimpin yang akan diminta pertanggungjawaban atas kepemimpinan kalian".

(Imam Nawawi, 2010, p. 122).

Analisis di atas berusaha untuk menjelaskan bahawa soal kerukunan rumah tangga menjadi perkara penting yang terkandung dalam ajaran Islam. Pemahaman ini diasaskan pada tafsiran serta huraian terhadap ayat al-Quran dan hadis yang dinyatakan di atas. Berdasarkan pemahaman ini, dapat dirumuskan bahawa mesej tentang kerukunan rumah tangga yang digarap dalam seni kata dikir al-Burdah yang dikaji adalah seiring dengan ajaran agama Islam.

\section{KESIMPULAN}

Secara keseluruhannya, kajian ini berhasil dalam menganalisis seni kata lagu dikir al-Burdah yang dikaji. Dari segi struktur, semua seni kata memperlihatkan penggunaan antaranya empat hingga tujuh buah rangkap, yang mengandungi antara satu hingga 12 baris, manakala setiap baris pula mengandungi antara satu hingga tujuh perkataan. Selain itu, seni kata yang dikaji juga didapati menggunakan rima akhir $\mathrm{a} / \mathrm{a} / \mathrm{a} / \mathrm{a}, \mathrm{a} / \mathrm{b} / \mathrm{a} / \mathrm{b}, \mathrm{a} / \mathrm{a} / \mathrm{b} / \mathrm{b}$, $\mathrm{a} / \mathrm{b} / \mathrm{a} / \mathrm{b} / \mathrm{a} / \mathrm{b}, \mathrm{a} / \mathrm{b} / \mathrm{a} / \mathrm{a} / \mathrm{b} / \mathrm{a}$, selain terdapat juga penggunaan rima akhir bebas yang tidak terikat dengan pola tertentu. Dari segi jumlah rangkap, baris dan perkataan, serta penggunaan rima akhir yang sedemikian, dapat dikatakan bahawa seni kata lagu dikir al-Burdah yang dikaji memperlihatkan bentuk yang sederhana; tidak terlalu tegar dengan bentuk serta pola tertentu. Keluwesan dari segi aspek struktur serta bentuk seni kata ini yang tidak 
terlalu terikat ini dengan sendirinya memberikan kebebasan yang lebih terhadap aspek isi kandungan. Dengan kata lain, struktur serta bentuk yang sedemikian memberikan gambaran bahawa seni kata lagu dikir al-Burdah lebih mengutamakan isi kandungan, berbanding bentuk.

Lanjutan daripada keutamaan terhadap isi kandungan, analisis ini mendapati bahawa kesemua seni kata lagu dikir al-Burdah yang dikaji mengutarakan mesej kerukunan rumah tangga. Pengutaraan mesej ini dimungkinkan dengan penggunaan beberapa bentuk pernyataan. Antara yang paling banyak digunakan ialah bentuk nasihat yang diisi dengan pesanan yang mengingatkan bahawa ikatan perkahwinan merupakan satu ikatan janji setia yang termeterai hingga ke akhir hayat, yang tidak terlepas daripada cabaran. Dalam konteks pesanan yang sedemikian, seni kata lagu yang dikaji turut menggunakan pernyataan yang bersifat peringatan yang antaranya menganjurkan pasangan suami isteri menyemai akhlak yang mulia dengan sifat sabar, tabah, pemaaf, bertolak ansur, jujur, saling bersatu padu serta tidak bertelagah. Selain itu, diselitkan doa untuk memohon kepada Allah SWT supaya rumah tangga yang dibina dikurniakan rahmat serta kebahagiaan hingga ke akhir hayat. Dalam konteks ini, terdapat seni kata lagu yang menurunkan kalimah yang bersumber al-Quran seperti Alhamdulillah, Lailahaillallah, Muhammadurrasulullah, Allah dan Bismillah. Selain itu, terdapat juga seni kata yang menghadirkan ungkapan pujian terhadap pasangan pengantin akan keelokan rupa paras, atau kesepadanan mereka sebagai suami isteri. Turut disebut antaranya pemakaian inai pada jari pasangan pengantin yang telah menjadi adat perkahwinan masyarakat Melayu. Beberapa buah seni kata didapati cenderung menggambarkan kemeriahan suasana majlis perkahwinan dengan memerikan bunyi-bunyian seperti paluan gendang untuk menyambut pasangan pengantin, zikir yang berkumandang, juadah yang disediakan, para tetamu yang hadir. Tidak ketinggalan diperikan ialah beberapa adat kebiasaan dalam upacara persandingan seperti renjisan air mawar dan bunga rampai. Kesemuanya pernyataan ini berupaya memerikan suasana majlis perkahwinan yang meriah. Selain itu, terdapat juga seni kata lagu yang menghadirkan pernyataan yang dapat mewakili perasaan pasangan pengantin yang antaranya menyebut perihal perasaan yang bahagia kerana hajat untuk diijabkabulkan sebagai suami isteri telah terlaksana, atau perasaan cinta termasuk janji untuk sehidup semati dengan pasangan. Kesemua pernyataan ini membangkitkan nuansa percintaan yang mengikat perasaan antara pasangan mempelai. Seperti yang telah dinyatakan, bentuk 
pernyataan ini memperkukuh pengutaraan mesej tentang kerukunan rumah tangga yang didapati mengisi seni kata lagu dikir al-Burdah yang dikaji.

Seterusnya, dan tidak kurang penting ialah dapatan bahawa mesej tentang kerukunan rumah tangga yang diutarakan dalam seni kata lagu dikir al-burdah yang dikaji juga sejajar dengan ajaran Islam, seperti yang terkandung dalam al-Quran dan Hadis. Dapatan ini dengan sendirinya menjelaskan tentang kesesuaian dikir al-burdah sebagai satu seni persembahan yang lazimnya dipersembahkan dalam majlis perkahwinan masyarakat Melayu di Sarawak.

\section{RUJUKAN}

Abang Yusuf Puteh. (2008). Adat perkahwinan orang Melayu Sarawak. Edisi Kedua. Kuala Lumpur: Dewan Bahasa dan Pustaka.

Abdul Halim Ali. (2006). Mendekati puisi Melayu tradisional. Tanjung Malim: Penerbitan Profesional Baharu.

Haji Abdul Malik Abdul Karim Amrullah (Hamka). (1984a). Tafsir al-Azhar juzu' 18-19-20-21. Surabaya: Yayasan Latimojong.

Haji Abdul Malik Abdul Karim Amrullah (Hamka). (1984b). Tafsir al-Azhar juzu' 4-5-6. Jakarta: Yayasan Nurul Islam.

Hj. Muhammad Bukhari Lubis. (1994). "Dendangan puisi al-Burdah di Kampung Sessang, Sarawak". Persuratan Islam. Kuala Lumpur: Dewan Bahasa dan Pustaka.

Harun Jaafar. (2002). "Puisi-puisi memuji Rasulullah". Wacana kesusasteraan Melayu klasik. Tanjong Malim: Penerbit Universiti Pendidikan Sultan Idris.

Harun Mat Piah. (1989). Puisi Melayu tradisional: Satu pembicaraan genre dan fungsi. Kuala Lumpur: Dewan Bahasa dan Pustaka.

Hj. Abd. Kadir Hj. Abdullah Hassan. (2002). Perkahwinan dalam Islam. Kuala Lumpur: Al-Hidayah Publishers.

Ibnu Katsier. (1988). Terjemahan singkat tafsir Ibnu Katsier. Jilid 2. Terj. H. Salim Bahreisy \& H. Said Bahreisy. Kuala Lumpur: Victory Agencie.

Ibnu Katsier. (1994). Terjemahan singkat tafsir Ibnu Katsier. Jilid 6. Terj. H. Salim Bahreisy \& H. Said Bahreisy. Kuala Lumpur: Victory Agencie.

Kamus Dewan. (2010). Edisi keempat. Kuala Lumpur: Dewan Bahasa dan Pustaka. Imam Nawawi. (2010). Riyadhus Shalihin: Perjalanan menuju taman surga. (Penerjemah: Zenal Mutaqin et al.). Bandung: Penerbit Jabal.com.

Jefferson, A. \& Robey, D. (eds). (1988). Teori kesusasteraan moden: Pengenalan secara perbandingan. Diterjemah oleh Mokhtar Ahmad. Kuala Lumpur: Dewan Bahasa dan Pustaka.

Junaidah Ameng. (2018). Keunggulan adat resam Melayu Sarawak pada hari raya Aidil fitri. Kota Samarahan: Junaidah Ameng. 
Mana Sikana. (2012). Teori sastera kontemporari. Edisi VIII. Selangor: Penerbit Pustaka Karya.

Mohd. Taib Osman. (1979). "Traditional Malay music: A traditional cultural expression in contemporary setting". Jurnal Budaya Melayu 4, 97-111.

Raslie Saharan. (1988). Beberapa aspek kebudayaan masyarakat Melayu Sarawak. Adat resam penduduk Sarawak. Jawatankuasa Kecil Publisiti dan Filem Perayaan Ulang Tahun Ke-25 Sarawak Merdeka dalam Malaysia. Hlm. 115170. Kuching: Dewan Bahasa dan Pustaka Cawangan Sarawak.

Sheikh Fuad Saleh. (2012). Melayari nikmat rumahtangga bimbingan buat mereka yang menempuh gerbang perkahwinan. (Penyusun: Ustaz Sharhan Safie). Batu Caves, Selangor: Pustaka Al Ehsan.

Stetkevych, S.P. (2010). The Mantle Odes: Arabic praise poems to the Prophet Muhammad. Bloomington: Indiana University Press.

Ungku Maimunah Mohd. Tahir. (2010). Kedudukan ilmu dalam kesusasteraan teori \& praktis. Bangi: Institut Alam dan Tamadun Melayu (ATMA).

Wawancara dengan Tuan Haji Mohamed Usup bin Rahman pada 8 Mac 2013 (Jumaat), pada jam 3.00 petang, bertempat di kediaman Tuan Haji Mohamed Usup di Kampung Melango Baru, Saratok, Sarawak.

Wawancara dengan Tuan Haji Mohamed Usup bin Rahman pada 14 Julai 2017 (Jumaat), pada jam 5.00 petang, bertempat di kediaman Tuan Haji Mohamed Usup di Kampung Melango Baru, Saratok, Sarawak.

Received: 3 September 2018

Accepted: 3 October 2018 